\title{
Current practice of bedside teaching in undergraduate medical education of Bangladesh
}

\author{
Jobaida Sultana ${ }^{1}$, Iffat Ara', Humayun Kabir Talukder ${ }^{3}$, Md Manir Hossain Khan ${ }^{4}$
}

\begin{abstract}
Introduction: Bedside teaching is the cornerstone of clinical teaching for the health professions. Different strategies have emerged to make it more effective. Many of the environments and opportunities available for bedside teaching and learning have changed.
\end{abstract}

Methodology: This was a descriptive type of cross sectional study conducted in seven (three public and four private) medical colleges in Bangladesh over a period from July 2012 to June 2013 to determine the ways of conduction of bedside teaching in undergraduate medical education of Bangladesh. Total 30 Bedside teaching (BST) sessions conducted in the ward in Obstetrics and Gynaecology departments were observed by researcher herself and data was collected in a structured check list by using 5 points rubric (1-lowest quality, 5-highest quality). The checklist had four main sections- physical environment of bedside sessions, issues regarding patient's comfort and attitude towards patient, teaching tasks and group dynamics. Each section had a number of items and total 27 items were observed. For each variable frequency distribution, mean score and standard deviation (SD) were calculated.Here mean score 5- no need of further improvement, as it covered all the required criteria, 4- very minimum effort, 3 - some effort, 2 = moderate effort, $1=$ considerable efforts are needed to fulfill the required criteria.

Result: Among physical environment factors the mean score of temperature, noise, space, teacher-student ratio were $>2$ but $<3$ and for light the mean score was $>3$ but $<4$. Among the issues regarding patient's comfort and attitude toward patient the mean scores on introducing everyone to the patient, maintaining privacy, explaining findings to the patient, genuine encouraging closure were $>1$ but $<2$ and on taking consent from the patient, showing appropriate attitude toward patient, teaching based on data about that patient were $>2$ but $<3$. Among teaching tasks the mean score on supervision of student during history taking, giving chance to practice the skills of the session, summarizing the session were $>1$ but $<2$ and on selection of the patient, supervision of student during physical examination, giving feedback, acting as a role model in physician- patient interactions, duration of the classes were $>2$ but $<3$ and on assisting a student during practicing a skill when needed, asking students to apply clinical reasoning skills were $>3$ but $<4$. Among group dynamics the mean score on active participation of the students and setting tasks for individual student were $>1$ but $<2$ and on setting goals for the group at the beginning of the class and setting time limit for every task were $>2$ but $<3$ and on active participation of the patients were $>3$ but $<4$.

Conclusion: In all aspects of bed side teaching minimum to considerable efforts are necessary to make it more effective. A bedside teacher must know the importance of comfortable physical environment in learning and must learn how to involve patients and learners in the educational process, so faculty development is essential.

\section{Introduction}

Teaching at the bedside is defined as teaching in the presence of the patient, taking place in natural health related environments ${ }^{1}$.Bedside teaching occurs during dedicated teaching at the bedside, work rounds, teaching rounds, review of admission and patient care, teaching in outpatient clinic, operation theatre and in emergency department. There

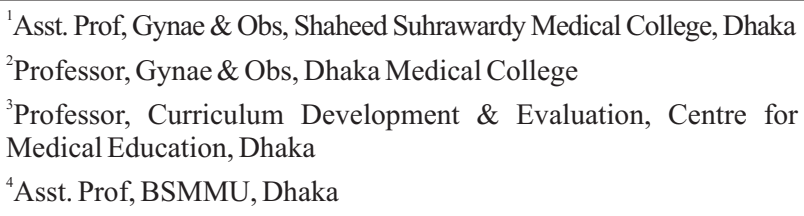

Address of correspondence: Dr. Jobaida Sultana, Asst. Prof. Dept. of Gynae \& Obs, Shaheed Suhrawardy Medical College, Dhaka E-mail: jobaidasultana@gmail.com should be "no teaching without the patient for a text, and the best teaching is often that taught by the patient himself" These are the words of one of the best-loved clinicianeducators, William Osler, who strongly believed in teaching students at the patient's bedside. Bedside teaching can improve students' history taking, examination skills, and knowledge of clinical ethics, can teach them professionalism, and can foster good communication and role modeling skills $^{2,3}$. The educational sessions integrate theory, practical skills, and patient contact to make the educational process as realistic as possible, and they allow the students to develop empathy with the patients ${ }^{4}$. Teaching small groups in the presence of the patient allows trainees to be closely observed and taught clinical practice and medical examinations.

In clinical medicine, $56 \%$ of patients' problems can be diagnosed after taking a comprehensive history, and this rises

Bangladesh Journal of Medical Education 2013;4(1):2-7. C 2013 Sultana et al., publisher and licensee Association for Medical Education. This is an Open Access article which permits unrestricted non-commercial use, provided the original work is properly cited. 
to $73 \%$ by the end of a physical examination ${ }^{5}$. The use of nose, ears and hands of a doctor other than technology is the best way to reach a diagnosis and to ensure a strong connection with the patient. It also saves time and money. Besides these educational advantages, there is evidence that patients favor bedside teaching and report better understanding of their illness after participating in bedside teaching ${ }^{6}$.

Despite the fact that bedside teaching is acknowledged for the unique benefits which it brings to the student's learning, the time allocated to bedside teaching has been shown to be on the decline. El-Bagir and Ahmed ${ }^{5}$ reported a decline from ' $75 \%$ of teaching time 30 years ago to just $16 \%$ by 1978 ' and note that it is much lower now. Ramani et al. ${ }^{7}$ reported that estimates of actual time spent at the bedside vary from $15 \%$ to $25 \%$. El-Bagir and Ahmed ${ }^{5}$ go on to say that bedside teaching 'has been neglected and rendered haphazard, mediocre and lacking in intellectual excitement, so much so that the clinical examination skills of young doctors have been seriously compromised'. Only $48 \%$ of learners reported that they had been given enough bedside teaching during their undergraduate training, while $100 \%$ thought that bedside learning was the most effective way of learning clinical skills ${ }^{8}$. Several barriers to bedside teaching have been identified ${ }^{9,10}$. Expert educators on bedside teaching have recommended many strategies to make it effective $\mathrm{e}^{2,9,11-13}$.

Bangladesh is a country of low socioeconomic status. Most of the people live in village. The laboratory facilities are very much limited especially in rural area. Most of the people cannot afford costly investigations. So, doctors have to depend on their clinical skills. Now the expectation of the people has changed. They want to know details about their problems expect good behavior and respect from the doctors. These clinical skills and communication skills are best learnt at bed side.

Now the importance in providing quality in medical education has been recognized. Many of the environments and opportunities available for bedside teaching and learning have changed dramatically in the last 20 years - increased importance of competency based clinical teaching, increased accountability \& increased patient autonomy and changes in knowledge about how students learn. The current practice of bedside teaching is not known in our country.

Therefore this study was designed to investigate the ways of conduction of bedside teaching in different medical colleges in Bangladesh. On the basis of result of which policy makers, educators, researchers can take the different steps and strategies to make bedside teaching more effective.

\section{Methodology}

This descriptive type of cross sectional study was carried out in seven (three public and four private) medical colleges in and around Dhaka city in Bangladesh over a period from July 2012 to June 2013. This study was done in Obstetrics and Gynaecology departments. Convenient sampling method was used for this study.

Total 30 Bedside teaching sessions (16 from public and 14 from private medical colleges) conducted in Obstetrics and Gynaecology departments were observed by researcher herself. Bedside teaching sessions held in morning, in the ward were included only. The sessions conducted in outpatient's department, operation theatre, emergency department were excluded from this study. Checklist with a five point rating by using rubric (1-lowest quality, 5-highest quality) was used as data collection tools for observation of bedside teaching session. The checklist had four main sections- physical environment of bedside sessions, issues regarding patient's comfort and attitude towards patient, teaching tasks and group dynamics. Each section had a number of items and total 27 items were observed. In the checklist there was a space to write any other comments.

Permission was taken from the respective authority of the medical colleges. Then the researcher communicated with the concerned teachers who conducted the classes. A brief idea about this study was given to the teachers. Teachers of the classes were assured so they did not feel any hesitation in conducting the sessions. Data were collected by observing the whole time of bedside teaching session as an observer by the researcher herself. Data were noted from the classes anonymously as per rubric by using the structured checklist. Check lists were edited after collection and coded manually and were undergo processed and analyzed by using SPSS computer soft ware according to the objectives. For each variable frequency distribution, mean score and standard deviation (SD) were calculated. Interpretation of mean scores were as follows-

$5=\quad$ No need of further improvement, as it covered all the required criteria.

4 to $<5=$ Very minimum efforts are needed to fulfill the required criteria.

3 to $<4=$ Some efforts are needed to fulfill the required criteria.

2 to $<3=$ Moderate efforts are needed to fulfill the required criteria.

1 to $<2=$ Considerable efforts are needed to fulfill the required criteria.

There was no ethical problem because all the information was collected after getting permission from the respective authority and confidentiality of the data was maintained.

\section{Result}

\section{Physical environment of bedside teaching in the ward}

Mean scores of temperature, noise, space, light and teacherstudent ratio were shown in Table-1. It was observed that in $70 \%$ classes the temperature was not so comfortable but students were not concerned about it, $77 \%$ classes there were presence of noise which sometimes caused disturbance, in $60 \%$ classes, space is such so that $<80 \%$ students have the scope to observe all the activities with the patients.

Bangladesh Journal of Medical Education 2013;4(1):2-7. 
Table I: Distribution of the classes according to the physical environment of bedside teaching in the ward

\begin{tabular}{|l|l|}
\hline Characteristics & Mean \pm SD \\
\hline Temperature of the ward & $2.90(.548)$ \\
\hline Disturbance by noise & $2.70(.596)$ \\
\hline $\begin{array}{l}\text { Space available around the patient in the } \\
\text { ward }\end{array}$ & $2.83(1.147)$ \\
\hline Sufficiency of light & $3.30(.988)$ \\
\hline Teacher-Student ratio & $2.13(1.042)$ \\
\hline
\end{tabular}

Rating used a scale of 1-5 ( 1 =Lowest quality, 5= Highest quality) by using rubric

\section{Issues regarding patient's comfort and attitude toward patient}

Mean scores on these issues were shown in Table-2. It was found that student took consent without explaining anything in $87 \%$ classes, no student was introduced with the patient in $100 \%$ classes, the issue regarding maintaining privacy was ignored in $40 \%$ classes and in another $40 \%$ classes they tried to maintain privacy but not happened, in $90 \%$ classes the team did not give any explanation to the patient, in $30 \%$ classes the issue regarding showing appropriate attitude toward patient was ignored and around $50 \%$ classes only few aspects were covered, in $47 \%$ classes $<60 \%$ time was used the data of this patient and most of the time discussed the theoretical aspect and $77 \%$ classes the students suddenly left the session without giving any thanks to the patient.

Table 2: Distribution of the classes on the basis of issues regarding patient's comfort and attitude toward patient

\begin{tabular}{|l|l|}
\hline Characteristics & Mean \pm SD \\
\hline $\begin{array}{l}\text { Taking consent of the patients by the } \\
\text { students }\end{array}$ & $2.93(.365)$ \\
\hline $\begin{array}{l}\text { Whether every student introduce } \\
\text { themselves with the patient }\end{array}$ & $1.0(0)$ \\
\hline Maintaining privacy of the patient & $1.83(.834)$ \\
\hline Explanation to the patient throughout & $1.10(.305)$ \\
\hline $\begin{array}{l}\text { Showing appropriate attitude toward } \\
\text { patient }\end{array}$ & $2.43(1.073)$ \\
\hline $\begin{array}{l}\text { Teaching based on data about that } \\
\text { patient }\end{array}$ & $2.37(.718)$ \\
\hline Genuine, encouraging closure & $1.23(.430)$ \\
\hline
\end{tabular}

Rating used a scale of 1-5 ( 1 =Lowest quality, $5=$ Highest quality) by using rubric

\section{Teaching tasks of the teachers}

It was found that in $20 \%$ classes the required patients were not found and in $54 \%$ classes the teacher selected the patients after starting the class time, in $80 \%$ classes the teacher did not supervise the students during history taking, in $37 \%$ classes the teacher did not supervise the students during physical examination, in $64 \%$ classes $<30 \%$ students were given chance to practice the skills of the session, in $60 \%$ classes sometimes teacher assisted a student during practicing a skill when needed, in $47 \%$ classes teacher asked students to apply few clinical reasoning skills, in $64 \%$ classes teacher gave feedback only on few aspects, in $70 \%$ classes teacher did not summarize the session, in $87 \%$ classes teacher did not act as a role model in physicianpatient interactions and in $60 \%$ classes the duration of classes actually held was $<1$ hour 15 min among 2 hour classes. Mean scores on these points were shown in Table-3.

Table 3: Distribution of the classes on the basis of the teaching tasks of the teachers

\begin{tabular}{|l|l|}
\hline Characteristics & Mean \pm SD \\
\hline Selection of the patient & $2.60(1.070)$ \\
\hline $\begin{array}{l}\text { Supervision of student during history } \\
\text { taking }\end{array}$ & $1.53(1.167)$ \\
\hline $\begin{array}{l}\text { Supervision of student during physical } \\
\text { examination }\end{array}$ & $2.30(1.236)$ \\
\hline $\begin{array}{l}\text { Giving chance to practice the skills of } \\
\text { the session. }\end{array}$ & $1.50(.777)$ \\
\hline $\begin{array}{l}\text { Assisting a student during practicing a } \\
\text { skill when needed }\end{array}$ & $3.40(.498)$ \\
\hline $\begin{array}{l}\text { Teacher asked students to apply clinical } \\
\text { reasoning skills }\end{array}$ & $3.87(.730)$ \\
\hline Giving feedback & $2.90(.607)$ \\
\hline Teachers summarize the session & $1.50(.820)$ \\
\hline $\begin{array}{l}\text { Teacher act as a role model in } \\
\text { physician- patient interactions }\end{array}$ & $2.23(.679)$ \\
\hline Duration of the class & $2.70(1.466)$ \\
\hline
\end{tabular}

Rating used a scale of 1-5 ( 1 =Lowest quality, 5= Highest quality) by using rubric

\section{Group dynamics of the session}

It was found that in $83 \%$ classes, $<50 \%$ students were actively participated, in $60 \%$ classes, patients delivered her history but not enthusiastically, in $83 \%$ classes teachers set the general objectives but not the specific objectives, in 100 $\%$ classes, $<50 \%$ students were given individual task and in $53 \%$ classes the team not aware of time and 33\% classes the team did their task according to time but not set up time limit. Mean scores on these factors were shown in Table-4. 
Table 4: Distribution of the classes on the basis of group dynamics of the session

\begin{tabular}{|l|l|}
\hline Characteristics & Mean \pm SD \\
\hline Active participation of the students & $1.23(.568)$ \\
\hline Active participation of the patients & $3.30(.651)$ \\
\hline $\begin{array}{l}\text { Setting goals for the group at the } \\
\text { beginning of the class. }\end{array}$ & $2.07(.521)$ \\
\hline Setting tasks for individual student & $1.00(0)$ \\
\hline Setting time limit for every task & $2.20(.664)$ \\
\hline
\end{tabular}

Rating used a scale of 1-5 ( 1 =Lowest quality, $5=$ Highest quality) by using rubric

\section{Discussion}

Since clinical practice involves the diagnosis and management of the problems in patients, clinical teaching should be carried out on real patients with real problems ${ }^{8}$. Demonstrating communication skills and physical examination findings, teaching humanistic aspects of clinical medicine, passing 'bad news' and modeling professional behaviors are some essential elements of patient care which cannot be effectively taught in a classroom and require the presence of patient. The patient's bedside however appear to be one of the most challenging settings for clinical teachers. In curriculum for undergraduate medical education in Bangladesh (2002), $4^{\text {th }}$ year and $5^{\text {th }}$ year students are placed in Obstetrics and Gynaecology department. Clinical schedule was in the morning for two hours and in the evening for two hours. In this study, only morning classes were observed because teachers of all ranks take the class in the morning, class time is fixed and students' attendance usually high.

Among physical environments factors, except light the mean scores of temperature, noise $\&$ space were low which is similar to other studies where it was reported that physical clinical environment is not suitable for teaching ${ }^{14}$. Among 30 classes in 20 classes the students were $>11$ in number. Among 7 medical colleges only in one medical college total students were divided into groups and placed in different units of that department, where students' number in each group was 10 . Students usually between two and five are quoted as optimal number for bedside teaching ${ }^{15}$. Evaluation of bedside teaching done by Green-Thompson et al $(2010)^{16}$ reported that in each group there were five students.

Rapport building with patients is very important and without patients cooperation it could be impossible for students to gain the necessary level of training and experience required for their qualification as doctors ${ }^{17}$. There is no doubt that interpersonal communication problems are a major source of patient dissatisfaction and patient non-compliance. The mean scores on the issues regarding patient's comfort and attitude toward patient were low in this study. The result of teaching based on data about that patient- is consistent with other studies ${ }^{14,18}$, where it was found that theories were taught more than practical teaching on this patient.

Teacher should select patients who would make for good bedside teaching well ahead of the class ${ }^{1}$. From this study it was found that $55 \%$ classes' teacher selected the patients but they selected the patient after starting the class time \& $20 \%$ classes the required patients were not found. Required patient not found in private medical colleges was mainly due to less patient got admitted in those hospitals \& in public hospitals there were lot of patients but due to fixed topic the required patients were not found on that day.

Mean score on supervision of student during history taking was $<2 \&$ of physical examination was $<3$, so considerable to moderate efforts are necessary to fulfill the required criteria. An overwhelming number of cases instructors neglect to observe trainees doing a history or physical exam $^{19}$. The result is that students develop inefficient or frankly wrong practice habits based on their perceptions of how interviewing and examination should be carried out. In order to achieve active learning, all students must be allowed to actively take part in interaction with the patients and make independent decisions regarding patient diagnosis and management. The optimal approach to achieve this would involve students seeing patients on a one to one basis ${ }^{20}$. In $65 \%$ classes $<30 \%$ students were given chance to practice the skills of the session.

Mean score on teacher asked students to apply clinical reasoning skills was 3.87 , so some effort is necessary to fulfill the required criteria. In one study it was observed that teachers most of the time did the passive actions- asking closed questions, demonstrating a procedure, sharing knowledge in didactic manner other than asking open ended questions or to apply clinical reasoning skills ${ }^{13}$.

The mean score on giving feedback by the teacher to the students was 2.90. From different studies it was found that clinical teachers either omit to give feedback altogether or the quality of their feedback does not enlighten the learners of their strengths and weakness ${ }^{14}$. One of the reasons behind this inappropriate feedback is failure to observe the trainee's performance during history taking \& physical examination which is similar to this study ${ }^{14}$. From the observation, the mean score on teachers summarize the session was 1.50. This teaching skill can be acquired if the teachers are provided with adequate training in medical education.

Around $87 \%$ classes the teachers did not act as a positive or negative role model in physician-patient interactions. The role modeling technique was not appropriately seen because physician-patient interactions were less happened in bed side teaching. In a study, it was found that when students are asked to rate how often they had witnessed a clinical teacher acting unethically, $61 \%$ of students reported that this happened to them very frequently, frequently, occasionally, where unethical behavior was considered as negative role model $^{21}$. 
The mean scores on duration of the class actually held were low. From observation it was found that sometimes teachers were ready to teach but students came lately. Sometimes students came in time but busy clinical teachers engaged in clinical activities. These two factors affected on duration of the class. A focus group study ${ }^{22}$ was done with undergraduate medical students and found that there were frequent cancellation or rescheduling of the clinical classes and students believed that the consultant was too busy in doing other things.

In this study, the mean scores on active participation of the students were low. An observational study ${ }^{13}$ revealed a dominance of passive and low level cognitive actions across learning sessions, particularly bedside teaching. The mean scores on setting goals for the group \& setting task for individual at the beginning of the class were low. One of the common problems of BST session is lack of clear objectives and expectations ${ }^{14}$.

In this study, teachers were informed previously before observation of their classes. Even though the scores were low because of lack of bedside teaching skills. Clinical teachers have a dual role in medicine, to provide patient care and to teach ${ }^{23}$. Though all doctors are well prepared for their clinical roles, few are trained for their teaching roles ${ }^{24}$. Most lack knowledge of educational principles and teaching strategies, thus may be inadequately prepared for this additional professional role $\mathrm{r}^{25}$. So, all clinical teachers should be provided with the training on bedside teaching. Along with this, provision of adequate facilities on the ward for bedside teaching, introduction of reward systems of teachers for good teaching, protected time for teaching, incorporation of ward staffs, written information of patient about bedside teaching and dividing the students in small group enhances the bed side teaching experience for patients, students and teachers.

\section{Conclusion}

Bedside teaching is a demanding, complex and often difficult task, a task many clinicians assume without adequate preparation or orientation. The clinical teacher needs to be aware of not just the learner but also of the welfare of the patient. In all aspects of bedside teaching minimum to considerable efforts are necessary to make it effective. Clinicians do not become teachers by virtue of their medical expertise, but a reflective approach to teaching and professional development can foster excellence in clinical teaching, so faculty development is essential.

\section{References}

1. Gill, D. Teaching and Learning 'At the Bedside'. Avilable from www. faculty. londondeanery. ac. uk/ teaching and learning at the bedside; 2007.

2. Ramani S. Twelve tips to improve bedside teaching, Med Teacher 2003; 25:112-5.

3. Fitzgerald FT. Bedside teaching. West $J$ Med
1993;158:418-20.

3. Ray S \& Ganguli P. Bedside teaching. Avilable from Careers.brij.com/ careers/ advice /viewarticle.html2.d=20000377; 2009 .

4. Ahmed M El-Bagir K. What is happening to bedside teaching? Med Educ 2002; 36: 1185-8.

5. Lehmann LS, Brancati FL, Chen M, Roter D \& Dobs AS. The effect of bedside case presentations on patients' perceptions of their medical care. New England Journal of Medicine 1997; 336: 1150-1155.

6. Ramani S, Orlander JD, Strunin L, Barber TW. Whither bedside teaching? A focus group study of clinical teachers. Acad Med 2003 Apr; 78(4):384-90.

7. Nair B, Coughlan JL \& Hensley MJ. Student and patient perspectives on bedside teaching. Medical Education 1997;31:341346.

8. La Combe MA. On bedside teaching. Ann Int Med 1997; 126:217-20.

9. Nair B, Coughlan JL \& Hensley MJ. Impediments to bedside teaching. Med Educ 1998; 32: 159-62.

10. Janicik RW \& Fletcher KE. Teaching at the bedside: a new model, Medical Teacher 2003; 25(2): 127-130.

11. Reilly BM. Inconvenient truths about effective clinical teaching. Lancet 2007; 370: 705-711.

12. Young L, Orlandi A, Galichet B \& Heussler H. Effective teaching and learning on the wards: easier said than done? Medical Education 2009; 43: 808-817.

13. Ramani S \& Leinster S. AMEE Guide NO. 34: Teaching in the clinical environment. Medical Teacher 2008; 30:347-364.

14. Dent JA \& Harde, RM. A Practical Guide for Medical Teachers, London: Churchill Livingstone, 2001, pp. 97-105.

15. Green-Thompson L, Mcinerney P, Veller M. The evaluation of bedside teaching- an instrument for staff evaluation and student experiences: A pilot study at a South African university.SAJS 2010; 48(2): 50-52.

16. Chipp E, Stonely S \& Cooper K. Clinical placement for medical students: factors affecting patient involvement in medical education. Medical Teacher 2004; 26(2): 114-119.

17. Islam MS, Khan I, Talukder MHK \& Akhter N. Clinical teaching in Dermatology of undergraduate Medical students of Bangladesh. Bangladesh Journal of Medical Education 2010; 1(1): 16-20.

18. Mcleod PJ \& Harden RM. Clinial Teaching strategies for physicians. Medical Teacher 1985; 7(2): 173-189.

19. Sanson Fisher RW, Rolef IE \& Williams N. Competency based teaching: the need for a new approach to teaching clinical skills in the

Bangladesh Journal of Medical Education 2013;4(1):2-7. 
Sundergraduate medical course. Medical Teacher 2005; 27(1): 29-36.

20. Hicks LK, Lin Y, Robertson DW, Robinson DL \& Woodrow SI. Understanding the clinical dilemmas that shape medical students' ethical development: questionnaire survey and focus group study. BMJ 2001;322: 709-710.

21. Stark P. Teaching and learning in the clinical setting: a qualitative study of the perceptions of students and teachers. Medical Education 2003; 37: 975-982.
22. Prideaux D, Alexander H, Bower A, Dacre J, Haist S, Jolly B,et al. Clinical teaching: maintaining an educational role for doctors in the new health care environment. Med Educ 2000; 34: 820826.

23. Steinert Y. Staff development for clinical teachers. Clin Teach 2005; 2: 104110.

24. Wilkerson L, Irby DM. Strategies for improving teaching practices: a comprehensive approach to faculty development. Acad Med 1998; 73: 387396. 